\title{
The Emergence of a Circadian Pattern in Respiratory Rates: Comparison between Control Infants and Subsequent Siblings of SIDS
}

\author{
TOKE HOPPENBROUWERS, Ph.D., ${ }^{(37)}$ DEBRA K. JENSEN, B.A., JOAN E. HODGMAN, M.D.,
} R. M. HARPER, Ph.D., AND M. B. STERMAN, Ph.D.

Newborn Division of the Los Angeles County-University of Southern California Medical Center; Department of Pediatrics, University of Southern California School of Medicine; Sepulveda Veterans Hospital; Departments of Anatomy, Psychiatry, and the Brain Research Institute, University of California, Los Angeles, California, USA

\section{Summary}

The objective of the present study is to compare the emergence of a circadian respiratory pattern in subsequent siblings of SIDS and control infants to see whether the unique time and age of SIDS is correlated with altered circadian manifestations. During the first three months of life, a pattern in respiratory rates emerged which appeared to be the nightly portion of a circadian rhythm. Subsequent siblings of SIDS exhibited transient accelerated maturation of this circadian pattern. During the first month of life, minima in respiratory rates in quiet sleep occurred during the second and third intervals of the night in subsequent siblings, a pattern not seen until three months of age in control infants.

\section{Speculation}

Two recent reports suggest a developmental model in which a physiological deficit can bring about a transient acceleration in maturation. Glück et al. (9) demonstrated an accelerated pattern of lung development as measured by the appearance of phosphatidylglycerol in amniotic fluid as much as eight wk early in intrauterine growth-retarded fetuses. Minkowsky (23) presented preliminary data of increased levels of neurotransmitters such as serotonin and precursors in fetal rats with experimentally induced intrauterine malnutrition. It is tempting to speculate that accelerated maturation in electroencephalographic sleep frequencies and respiratory circadian patterns in subsequent siblings of sudden infant death syndrome are manifestations of a compensatory response to an oxygen deficit.

Although the risk of dying of the Sudden Infant Death Syndrome (SIDS) is only $2 \%$ for the subsequent sibling, this represents a 10-fold increase in risk as compared to the normal population $(7,26)$. Infants are at the highest risk for SIDS between six and 12 wk of age (2). The majority of infants die during normal sleeping hours and typically are seen alive at the last feeding before the parents' bedtime (33). Therefore, death must occur between midnight and 9:00 A.M., and autopsy reports have identified the morning hours shortly before normal waking as the most likely time of death $(3,33)$. A circadian pattern in heart rate and temperature emerges at six wh of age and coincides with the vulnerable age for SIDS (12).

In adults, several aspects of respiratory regulation exhibit circadian patterns. Reinberg and Gervais (28) showed an increased $\mathrm{CO}_{2}$ tension during sleep in the early morning hr. Tammeling $e t$ al. (32) found higher values for flow resistance in the airways during the hr past midnight, whereas subjects with colds exhibited increased levels of esophageal pressure at that time (32).

One group of investigators studied seven children between six and ten years of age and found the highest pulmonary resistance around 5:30 A.M. (8). In a previous report, we demonstrated the emergence of what seemed to be a circadian pattern in respiratory rates during the first six months of life in normal full-term infants (20). This pattern was characterized by decreased respiratory rates between approximately 10:00 P.M. and 4:00 A.M., as compared to either before or after that time. The objective of the present study is to compare the emergence of a circadian respiratory pattern in subsequent siblings of SIDS and control infants to see whether the unique time and age of SIDS is correlated with altered circadian manifestations.

\section{MATERIALS AND METHODS}

\section{MATERIALS AND MONITORING PROCEDURES}

Selection criteria for 25 control subjects included the absence of both maternal disease and familial incidence of SIDS. The experimental group consisted of 26 infants born to women who had lost an infant to SIDS as confirmed by autopsy reports. The two groups were homogeneous and comparable in respect to socioeconomic status as estimated by level of parental education. The experimental group consisted of 14 females and 12 males, whereas the control group had nine females and 16 males. Study group characteristics are provided in Table 1.

\section{PHYSIOLOGICAL RECORDING METHODS}

All infants were monitored for $12 \mathrm{hr}$ continuously in an infant sleep laboratory within the first two wk of life. They returned for similar recordings at one, two, three, four, and six months of age. Physiological and behavioral determinations included: two electroencephalographic recordings (EEG), a chin electromyogram, eye movements, somatic activity, an electrocardiogram, and three recordings of respiration. The latter included chest movements by impedance pneumography, expired $\mathrm{pCO}_{2}$, and phase of respiration as estimated through a nasal thermistor. Details of these procedures have been published previously $(13,15)$. All data were recorded on a 16-channel Grass model 78 polygraph and simultaneously stored on a 14-channel Honeywell analog tape recorder.

Each min of the record was coded as either Active Sleep (AS), Quiet Sleep (QS), Awake (AW) or Indeterminate (IN). Scoring criteria have been reported elsewhere $(11,15,30)$.

\section{DATA ANALYSIS}

The entire data set for each infant was digitized on a PDP-12 laboratory computer (11), and the $\mathrm{pCO}_{2}$ signal was submitted to a breath-to-breath interval detection program. This signal was selected for its reliability and resistance to movement artifacts. Median respiratory rates for each min were obtained $(14,22)$. To examine the emergence of a circadian pattern, the first min of 
Table 1. Study group characteristics

\begin{tabular}{lcc}
\hline Controls & $\begin{array}{c}\text { Subsequent sib- } \\
\text { lings }\end{array}$ \\
\hline
\end{tabular}

Maternal age

Mean

26. 10

S.D.

3.64

26.45

5.06

Maternal race

White

Black

Asian American

Latino

20

1

2

2

2.84

Mean

S.D.

Parity

Mean

S.D.

2.48

1.19

31.85

Total Weight Gain (Pounds)

Mean

S.D.

8.95

31.80

8.34

Birthweight (Grams)

Mean

S.D.

3575.

465

3594.

496

Gestational Age

Mean

40.78

1.64

40.06

S.D.

Sex

Males

Females

16

9

8.52

Apgar at $1 \mathrm{~min}$

Mean

S.D.

Apgar at $5 \mathrm{~min}$

Mean

S.D.

Age (in days) at time of monitoring

I wk

Mean

4.88

S.D.

1 month

Mean

S.D.

30.80

6.02

31.72

3.98

2 months

Mean

60.08

S.D.

3 months

Mean

S.D.

4 months

Mean

118.40

S.D.

8.72

6 months

Mean

S.D. sleep, either QS or AS, was identified, and the subsequent recording time was divided into four equal time intervals (Fig. 1). Although time of sleep onset and sleep duration varied among infants, the study groups were comparable in this respect. A computer program calculated the mean respiratory rate across each of the four intervals as a function of state. Respiratory rates in subsequent siblings were consistently higher than those from control infants $(16,17,19)$. The present paper does not compare differences in respiratory rates between subsequent siblings and controls, but describes the development of temporal patterns in respiration. Our previous study showed that respiratory rates in siblings and controls were distributed normally and that no subpopulation was responsible for the observed differences. Therefore, analysis of variance was considered the statistical treatment of choice. For each sleep state and study group, separate analyses of variance were performed with factors age and interval during the night $(6,35)$.

\section{RESULTS}

\section{EMERGENCE OF CIRCADIAN PATTERNS}

Immediate Neonatal Period. In control infants, a trend analysis revealed that mean respiratory rates increased linearly across the night in every state, including AW. In subsequent siblings, however, at this early age in AS and AW the respiratory patterns were already deviating from linearity, whereas QS and IN patterns were linear as in controls.

$A S$ and IN Circadian Patterns. In control infants, a significant quadratic trend was first seen in AS and IN at one month of age (Fig. 2; Table 2). Respiratory rates declined to a minimum level during the second interval of the night between approximately 10:00 P.M. and 1:00 A.M. and then began to rise slowly. An identical trend was observed at two and three months of age. At three months, however, the minimum respiratory rate was sustained across two intervals in AS and occurred during the third interval in IN, manifestations of increased maturity (12).

At four months of age, a quadratic trend still characterized IN respiratory rates across the night, whereas the AS rates now decreased linearly. At six months of age, no significant trends were observed (Fig. 3).

In subsequent siblings, the trend analysis revealed similar patterns (Table 2), but respiratory minima were already sustained for the duration of two intervals at one and two months of age. In other words, these infants exhibited characteristics of a more mature pattern earlier.

QS Circadian Patterns. In control infants, a linear increase in respiratory rates across the night was still present at one month of age, a cubic pattern characterized the second month of life, and a significant quadratic trend was observed at three months of age. This persisted throughout the remainder of the ages examined.

Subsequent siblings exhibited a quadratic trend at one month of age. In addition to this significant trend difference, the amplitude of the decrease in respiratory rate was greater and persisted across two time intervals, already showing a more mature configuration at one month of age (Fig. 2). At two months of age, the shape of the curves were comparable in the two study groups, whereas at three months control infants exhibited a more mature pattern.

Awake Respiratory Rates. In control infants, a linear increase in respiratory rates was seen at one month of age, and a quadratic trend was seen only at three months of age. No systematic trend was observed in subsequent siblings at any age during waking (Table 2).

\section{FEEDING PATTERNS}

Awakenings with and without feedings were plotted across the night for ten control and ten subsequent siblings at each age (Fig. 4). A comparison of these graphs indicates a difference in study groups. At three months of age, between 2:00 and 5:00 A.M., 
6MO

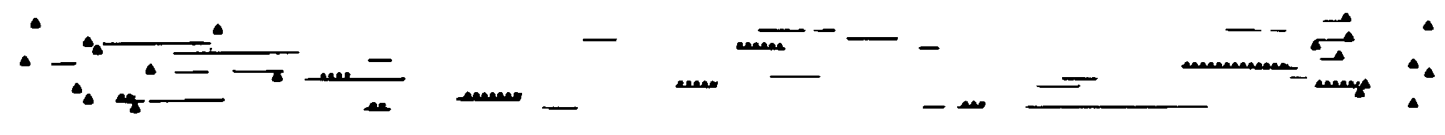

$4 \mathrm{MO}$

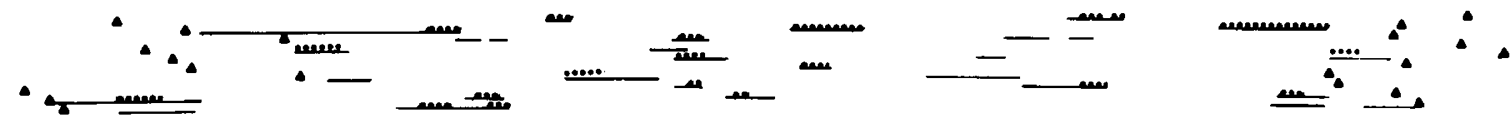

3MO
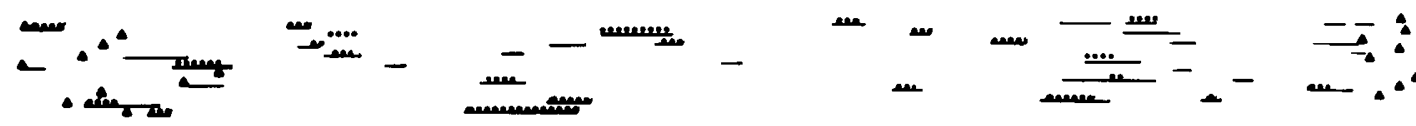

$\frac{1}{4}$

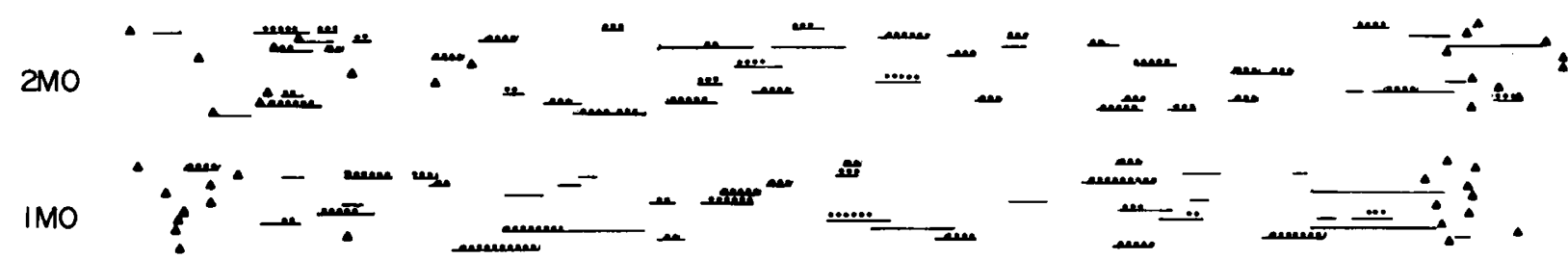

IWK
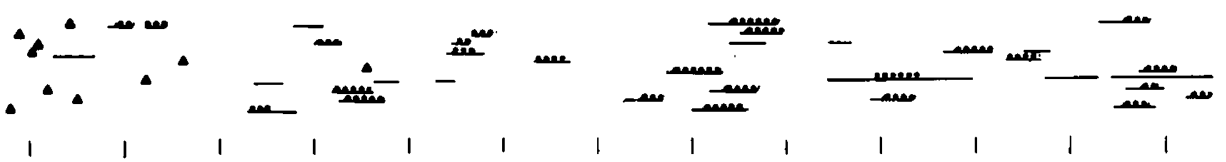

P.M. $6.00 \quad 650 \quad 7.40 \quad 830 \quad 920 \quad 1010 \quad 11.00 \quad 11.50 \quad 12.40 \quad 1.30$

TIME OF NIGHT

A

$6 \mathrm{MO}$
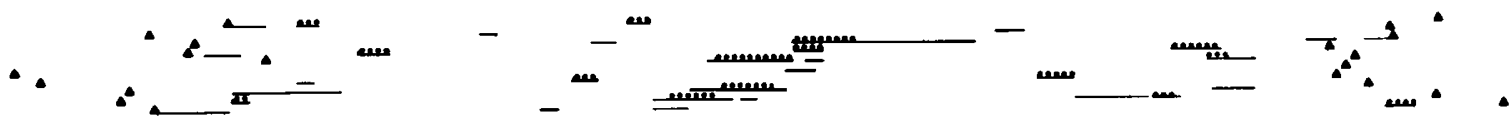

$4 \mathrm{MO}$
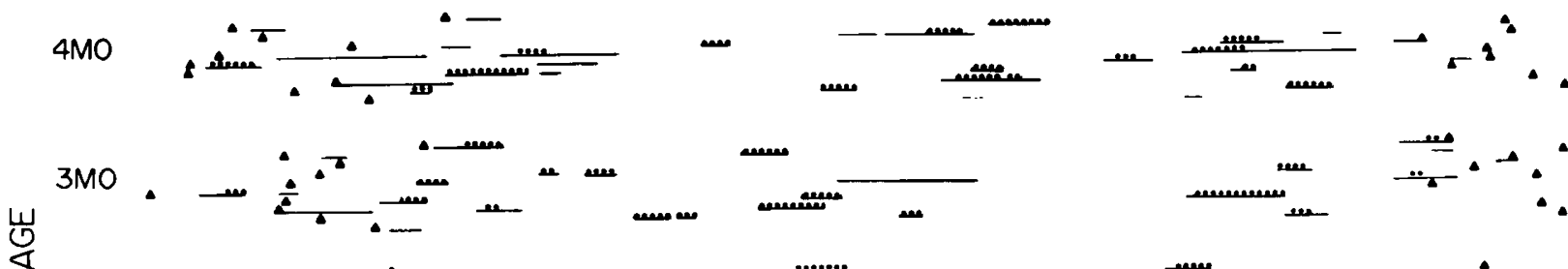

$\mathrm{MO}$
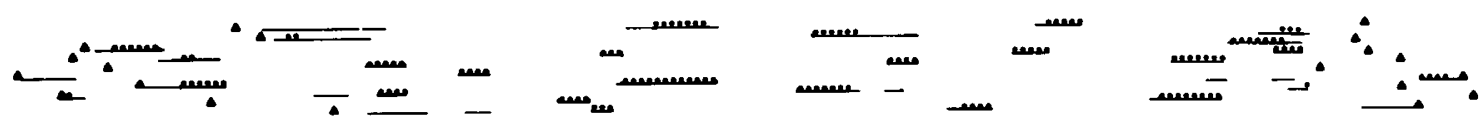

IMO
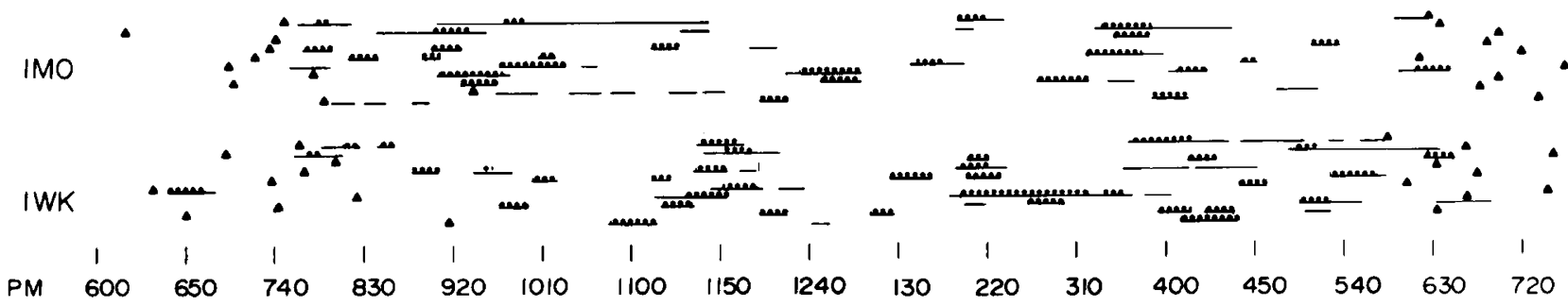

TIME OF NIGHT

$\mathrm{B}$

Fig. 1. $A$, graph of epochs of sustained wakefulness $(\geq 10 \mathrm{~min})$ in ten control infants at every age of recording. The order of the infant is identical at every age. $(\cdots)$, feeding episodes; $\Delta$, beginning and end time of each recording. Feedings are evenly distributed across the night, and the number decreased at four to six months of age; $B$, similar graphs as in $A$ from ten subsequent siblings of SIDS. Note paucity of feedings between approximately 2:00 and 5:00 A.M. at three months of age in these infants. 

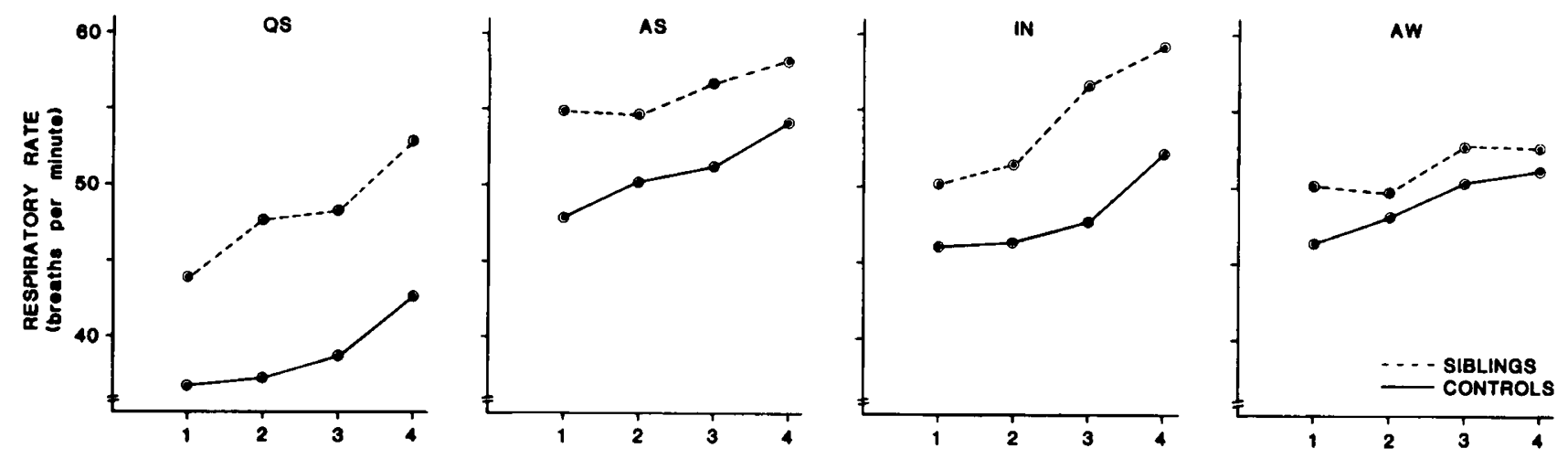

INTERVAL

Fig. 2. Graphs of the mean respiratory rate in breaths per min (ordinate) as a function of the interval during the night (abscissa). A significant linear increase characterized the respiratory rates across sequential intervals in one-wk-old control infants in every state $(-)$. Subsequent siblings of SIDS (- - -) exhibited this same trend in QS and IN respiratory rates, but not in AS and AW.

Table 2. $P$ Values for main interval effect and trend as a function of age and state

\begin{tabular}{|c|c|c|c|c|c|c|c|c|c|c|c|c|}
\hline & \multicolumn{2}{|c|}{ l wk } & \multicolumn{2}{|c|}{1 month } & \multicolumn{2}{|c|}{2 months } & \multicolumn{2}{|c|}{3 months } & \multicolumn{2}{|c|}{4 months } & \multicolumn{2}{|c|}{6 months } \\
\hline QS & 0.000 & $\operatorname{lin} 0.000$ & $\mathbf{N S}^{1}$ & $\operatorname{lin}^{2} 0.029$ & 0.031 & cub 0.030 & 0.002 & quad 0.000 & 0.002 & quad 0.001 & NS & quad 0.002 \\
\hline AS & 0.003 & $\operatorname{lin} 0.006$ & 0.012 & quad 0.003 & 0.005 & quad 0.001 & 0.002 & quad 0.002 & 0.020 & $\operatorname{lin} 0.040$ & NS & NS \\
\hline IN & 0.034 & $\operatorname{lin} 0.040$ & 0.001 & quad 0.001 & NS & quad 0.044 & 0.039 & quad 0.027 & NS & quad 0.019 & NS & NS \\
\hline
\end{tabular}

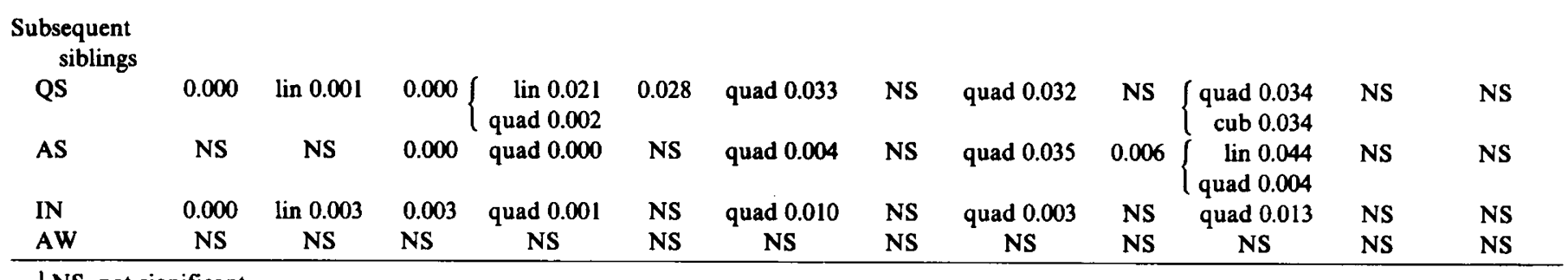

'NS, not significant.

${ }^{2}$ lin: linear; quad: quadratic; cub: cubic.

subsequent siblings appeared to wake up for feedings less frequently than did control infants. The mean, standard deviation, and range of the total number of feedings in each group at each age for the entire sample are provided in Table 3. No significant differences between study groups were found in the overall feeding patterns.

\section{COMPARISON OF INTERVAL MEANS}

Average respiratory rates at each of the four intervals were compared using an analysis of variance for each sleep state and study group (Table 4). In the newborn period, the mean AS, IN, and $A W$ respiratory rate during the last interval of the night was significantly elevated as compared to the first interval. In QS, the respiratory rate during the last interval was elevated compared to all previous intervals. In subsequent siblings, significant differences in means were restricted to QS and IN (Tables 2 and 4).

Control infants showed significant results in AS and IN at one and three months of age and in AS alone at two and four months of age, whereas in subsequent siblings, the differences occurred at one month in AS and IN and at four months in AS alone (Figs. 2 and 3). In control infants, significant differences in QS interval means were observed at two, three, and four months of age, whereas subsequent siblings only exhibited differences at one and two months (Figs. 2 and 3). Differences in means during AW were restricted to one month of age in control infants. No differences in $\mathrm{AW}$ interval means were observed in subsequent siblings.

\section{DISCUSSION}

A pattern emerged in respiratory rates with minima during the second and third intervals of the night, which appears to be the nightly portion of a circadian rhythm. In a previous report (20), we emphasized two observations in control infants. First, a circadian pattern appeared in AS and IN respiratory rates during the first month of life, two months before the appearance of a similar pattern in QS. Second, a circadian rhythm was observed in wakefulness as well as sleep at three months of age, suggesting that sleep alone cannot explain these changes in respiratory patterns. Data presented here revealed a third important observation. Siblings of SIDS exhibited transient, accelerated maturation of this circadian pattern. During the first month of life, a quadratic trend had appeared in QS respiratory rates in the siblings whereas control infants still exhibited a linear pattern characteristic of the first week of life. The minima in subsequent siblings already persisted for two intervals in all sleep states at one month. This difference in pattern was not maintained at following ages. From two months of age, the pattern in subsequent siblings resembled that of controls. 
CNE. TWO. THREE MONTHS

QS

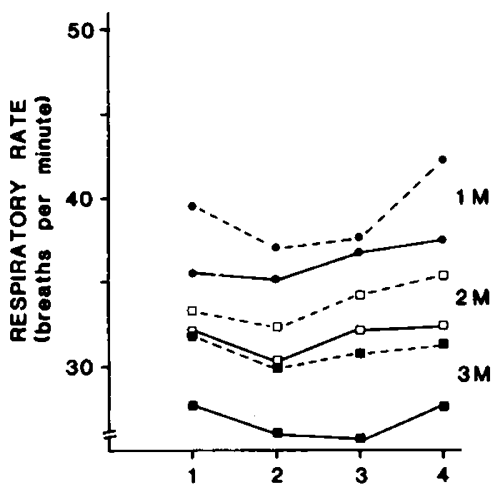

- . - - SIELNGS
AS

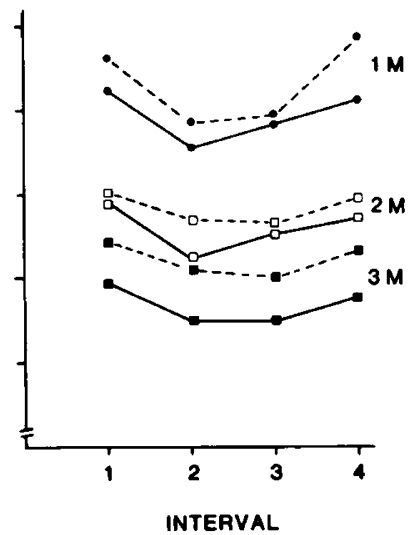

IN

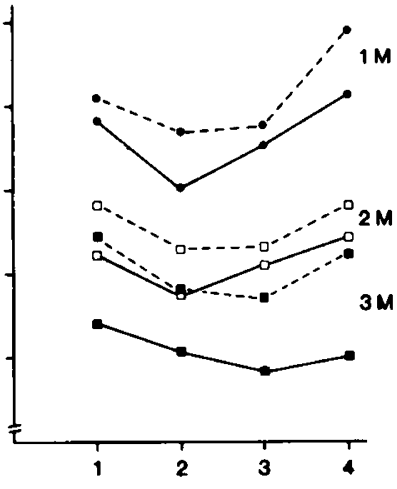

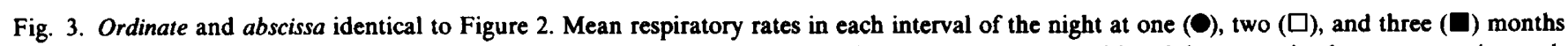
of age in QS, AS, and IN. C, clear circadian pattern at one month of age in siblings of SIDS with minima sustained across two intervals $(---)$. Control infants $(-)$ still exhibited a more immature pattern.

\section{FOUR SX MONTHS}

os

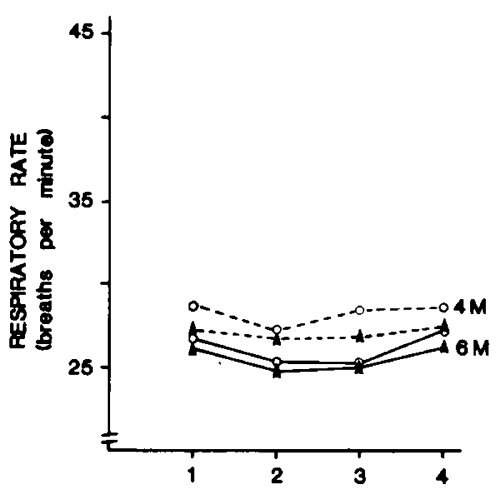

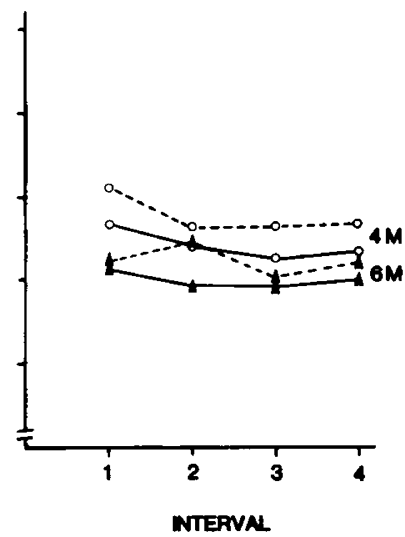

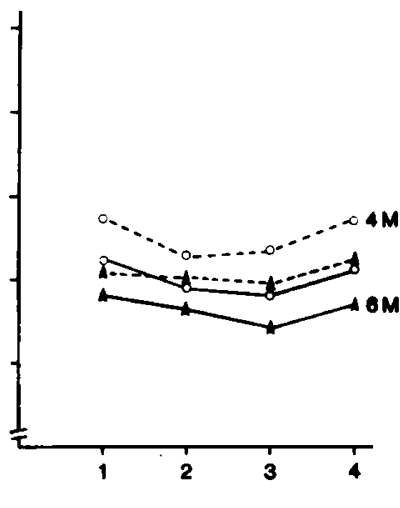

- - - - Sigunas

controls

OFOR MONTHS

$\triangle$ SX MONTHS

Fig. 4. Mean respiratory rates across four intervals during the night at four $(O)$ and six $(\Delta)$ months of age. The differences between subsequent siblings of SIDS and control infants have largely disappeared at these ages.

Table 3. Number of feedings throughout the night in controls and subsequent siblings

\begin{tabular}{llccccc}
\hline & 1 wk & $\begin{array}{c}1 \\
\text { month }\end{array}$ & $\begin{array}{c}2 \\
\text { months }\end{array}$ & $\begin{array}{c}3 \\
\text { months }\end{array}$ & $\begin{array}{c}4 \\
\text { months }\end{array}$ & $\begin{array}{c}6 \\
\text { months }\end{array}$ \\
\hline $\begin{array}{l}\text { Controls } \\
\text { Mean }\end{array}$ & 3.4 & 3.3 & 3.5 & 3.1 & 2.2 & 2.1 \\
S.D. & 0.8 & 1.3 & 1.6 & 1.1 & 1.2 & 1.7 \\
Siblings & & & & & & \\
Mean & 3.6 & 3.3 & 3.1 & 3.0 & 2.9 & 2.8 \\
S.D. & 0.88 & 1.3 & 1.1 & 1.0 & 1.7 & 1.4 \\
\hline
\end{tabular}

Hellbrügge (12), who studied the emergence of circadian patterns of temperature, heart rates, and urinary excretion of potassium and sodium, pointed out that maturation of the circadian pattern is manifested in an increased amplitude of the variation, a delay in the time of the minima and a prolongation of the minimum values. Rutenfranz (29) suggested that organs which mature earlier tend to show a 24-hr rhythm sooner. Even within a single organ, a different maturing process can lead to a different rate of development of the circadian pattern. Thus, renal excretion of water, depending primarily on glomerular function, showed a circadian rhythm before such a trend was observed in excretion of electrolytes, based primarily on tubular function. If the assumption of the correlation between maturation and the emergence of a circadian rhythm is correct, one can raise the question of whether the transient accelerated maturation in respiratory circadian patterns in siblings is accompanied by a similar acceleration in the maturation of sleep states. Although we did not observe any significant differences in amounts and durations of sleep states between siblings and control infants (18), a careful study of EEG. power spectral densities between 0 and $19 \mathrm{~Hz}$ in these same infants showed important study group differences. Control infants reached peak levels of power in these frequency components at 12 wk of life, whereas the subsequent siblings achieved peak levels four weeks earlier, thus suggesting accelerated maturation of sleep EEG frequencies in subsequent siblings (31). Alternately, the transient early emergence of a circadian pattern in respiratory 
Table 4. Significant differences in interval means as a function of age and state in respiratory rates ${ }^{1}$

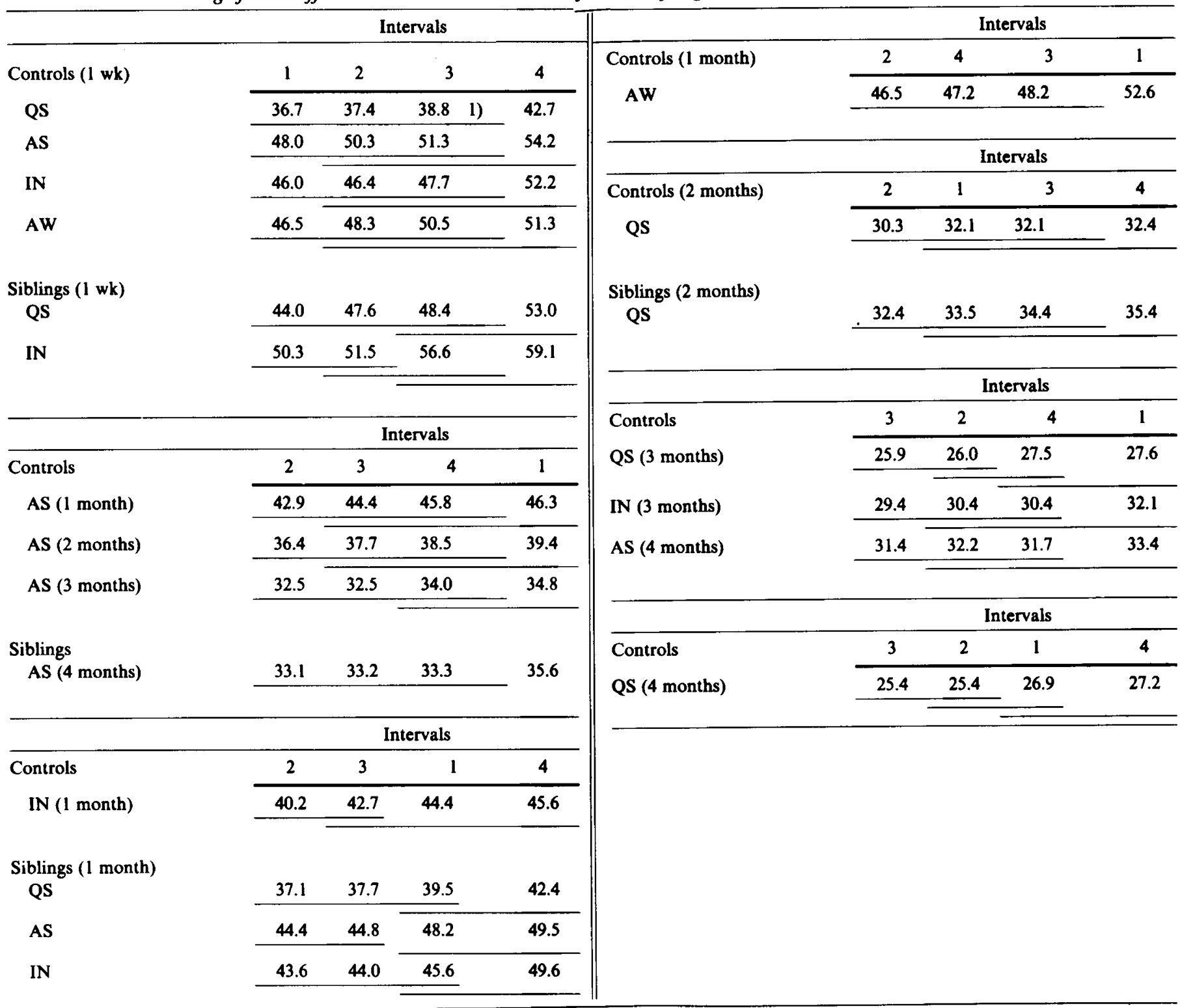

'Values are ordered from lowest to highest. Values not sharing an underline are significantly different from one another.

rates in siblings may reflect an altered maturational course of respiratory control mechanisms which are state specific. In the adult organism, Phillipson (27) reported that during QS, respiration is primarily under chemoreceptor control. Although chemoreceptors are responsive in the full-term neonate, data reported recently from monkeys demonstrated age-related differences in sensitivity (21). Such data, presently not available in the full-term infant, indicate the need to carefully examine ventilatory response during infancy for potential linear and nonlinear maturational changes.

Because all sleep states were affected to a degree at one month of age, altered exogeneous influences, such as periods of light and darkness (1), cannot be ruled out. At one month of age, 12 subsequent siblings were monitored between May and September, compared to 14 control infants, thus precluding an uneven contribution of length of day. Feeding cannot explain the differences between study groups at one month of age because feeding patterns were not different at this time (24).

Naeye (25) and Valdez-Dapena (34) have demonstrated pathologic changes in SIDS suggestive of chronic hypoxia preceding death. Increased respiratory rates in subsequent siblings are a possible compensation for mild chronic hypoxia. This is supported by a study of infants known to by hypoxemic who exhibited higher respiratory rates during quiet sleep (4). Successful compensatory behavior may characterize the majority of infants at increased risk for SIDS. If we assume that increased respiratory rates are a response to hypoxia in siblings, can the accelerated maturation of the circadian pattern be another compensatory response?

Factors which may predispose infants to increased risk for SIDS must be distinguished from those which actually precipitate death. The differences between subsequent siblings and controls presented here may elucidate mechanisms placing an infant at increased risk. At present, they cannot be considered markers to identify individual infants.

\section{REFERENCES AND NOTES}

1. Ashoff, J., and Wever, R.: Human circadian rhythms: a multioscillatory system. Fed. Proc., 35: 2326 (1976).

2. Beckwith, J. B.: The sudden infant death syndrome. Curr. Probl. Pediatr., 3: I (1973).

3. Bergman, A. B., Beckwith. J. B., and Ray, C. G.: Sudden Infant Death Syndrome (Univeristy of Washington Press, Seattle, 1970).

4. Brück, K., Adams, F. H., and Brück, M.: Temperature regulation in infants with chronic hypoxemia. Pediatrics, 30: 350 (1962). 
5. deHemos, R. A., Shermeta, D. W., Knelson, J., Kotas, R. V., and Avery, M. C.: Acceleration of appearance of pulmonary surfactant in the fetal lamb by administration of corticosteroids. Am. Rev. Respir. Dis., 102: 459 (1970).

6. Dixon, W. J.: Biomedical Computer Programs, p. 711 (University of California Press, Berkeley, 1975).

7. Froggatt, P., Lynas, M. A., and MacKenzie, G.: Epidemiology of sudden unexpected death in infants ("cot death") in Northern Ireland. Br. J. Prev. Soc. Med., 25: 119 (1971).

8. Gaultier, C., Reinberg, A., Girard, F., and Gerbeaux, J.: Rhythme circadien des facteurs mécaniques ventilatoires chez l'enfant sain. C. R. Acad. Sci., 280: 1253 (1975).

9. Glück, L., Kulovich, M. V., and Hallman, M.: Effects of chronic intrauterine asphyxia on organ maturation. In: L. Glück: Intrauterine Asphyxia and the Developing Fetal Brain. p. 93 (Yearbook Medical Publishers, Inc., Chicago, 1977).

10. Harper, R. M., Hoppenbrouwers, T., Sterman, M. B., McGinty, D. J., and Hodgman, J. E.: Polygraphic studies of normal infants during the first six months of life. I. Heart rate and variability as a function of state. Pediatr. Res. 10: 945 (1976).

11. Harper, R. M., Sclabassi, R. J., and Estrin, T.: Time sefies analysis and sleep research. IEEE Trans. Auto. Control AC-19, 6: 932 (1974).

12. Hellbrïgge, T.: The development of circadian rhythms in infants. Cold Spring Harbor Symp. Quant. Biol., 25: 311 (1960).

13. Hofmann, E., Havens, B., Geidel, S., Hoppenbrouwers, T., and Hodgman, J.: Long-term, continuous monitoring of multiple physiological parameters in newborn and young infants. Acta Paediatr. Scand. Suppl., 266 (1977).

14. Hoppenbrouwers, T., Harper, R. M., Hodgman, J. E., Sterman, M. B., and McGinty, D. J.: Polygraphic studies of normal infants during the first six months of life. II. Respiratory rate and variability as a function of state. Pediatr. Res., 12: 120 (1978).

15. Hoppenbrouwers, T., Hodgman, J. E., Harper, R. M., Hofmann, E., Sterman, M. B., and McGinty, D. J.: Polygraphic studies of normal infants during the first six months of life. III. Incidence of apnea and periodic breathing. Pediatrics, 60: 418 (1977).

16. Hoppenbrouwers, T., Hodgman, J. E., Harper, R. M., McGinty, D. J., and Sterman, M. B.: Respiratory rates and apnea in infants at high and low risk for sudden infant death syndrome (SIDS). Clin. Res., 25: 189A (1977).

17. Hoppenbrouwers, T., Hodgman, J. E., Harper, R. M., McGinty, D. J., and Sterman, M. B.: Incidence of apnea in infants at high and low risk for sudden infant death syndrome (SIDS). Pediatr. Res., 10: 425 (1976).

18. Hoppenbrouwers, T., Hodgman, J. E., Harper, R. M., Sterman, M. B., and Geidel, S. A.: Laboratory sleep state measurements in infants at low and increased risk for SIDS. Pediatr. Res, 12: 552 (1978).

19. Hoppenbrouwers, T., Hofmann, E., and Hodgman, J.: Cardiac responses to apnea in subsequent siblings of SIDS. Clin. Res., 23: 164A (1975).

20. Hoppenbrouwers, T., Jensen, D., Hodgman, J. E., Harper, R. M., and Sterman, M. B.: Respiration during the first six months of life in normal infants: the emergence of a circadian pattern. Neuropädiatrie, 10: 264 (1979).

21. Jacky, J. P.: Ventilatory responses to inhaled $\mathrm{CO}_{2}$ during sleep in the infant primate. Diss. Abstr. B. Sci. Eng. 1: 122 (1977).

22. Mason, J., Harper, R. M., and Pacheco, R.: Analysis of respiratory data during sleep and waking. Proc. Digital Equip. Comput. Users, p. 567 (1974).

23. Minkowski, A.: Unpublished data presented at Neonatal Grand Rounds, LACUSC Medical Center, Los Angeles, California (1978).

24. Moore-Ede, M. C., and Sulzman, F. M.: Physiological basis of circadian timekeeping in primates. Physiologist, 20: 17 (1977).

25. Naeye, R. L.: Hypoxemia and the sudden infant death syndrome. Science, 186 : 837 (1974).

26. Peterson, D.: Paper presented at the research reporting workshop for the National Institute of Child Health and Human Development, Sudden Infant Death Syndrome Grantees and Contracts (Alexandria, Virginia, 1977).

27. Phillipson, E. A.: Respiratory adaptations in sleep. Ann. Rev. Physiol., 46: 133 (1978).

28. Reinberg, A., and Gervais, P.: Circadian rhythms in respiratory functions with specific reference to human chronophysiology and chronopharmacology. Bull. Physiopath. Resp. 8: 663 (1972).

29. Rutenfranz, J.: The development of circadian system functions during infancy and childhood. In: Circadian Systems: 39th Ross Conference on Pediatric Research, p. 38 (Ross Laboratories, Columbus, Ohio, 1961).

30. Sterman, M. B., Harper, R. M., Havens, B., Hoppenbrouwers, T., McGinty, D. J., and Hodgman, J. E.: Quantitative analysis of central cortical EEG activity during quiet sleep in infants. Electroencephal. Clin. Neurophysiol., 43: 371 (1977).

31. Sterman, M. B., Hoppenbrouwers, T., Harper, R. M., and Hodgman, J. E.: Quantitative analysis of sleep EEG development in infants at high and low risk for sudden death. (in preparation, 1979).

32. Tammeling, G. J., Kruyt, E. W., Oliver, C. N., and Sluiter, H. J.: Circadian pattern of the ventilatory function in healthy subjects and patients with obstructive lung disease. Int. J. Chronobiology, 3: 155 (1976).

33. Valdes-Dapena, M.: Sudden death in infants. In: R. J. Wedgewood and E. P. Benditt: Public Health Service Publication \#1412 (U. S. Government Printing Office, Washington, D. C., 1974).

34. Valdes-Dapena, M.: Sudden infant death syndrome case analyses. Paper presented at the research reporting workshop for the National Institute of Child Health and Human Development, Sudden Infant Death Syndrome Grantees and Contracts (Alexandria, Virginia, 1977).

35. Winer, B. J.: Statistical Principles in Experimental Design (McGraw-Hill, New York, 1962).

36. The authors thank Ms. B. Havens, E. Hofmann, and S. Geidel for the development of the monitoring program and their contribution to the data collection. We also acknowledge the contribution of Mrs. K. Arakawa, M.A., and Mr. J. Mason.

37. Requests for reprints should be addressed to: Toke Hoppenbrouwers, Ph.D., Director, Sudden Infant Death Syndrome (SIDS), Research Project, Room 4LA0B, 1240 Mission Road, LAC/USC Medical Center, Los Angeles, CA 90033 .

38. This research was supported by the NIHCHD Contract \#NO1-HD-2777 and HD 4-2810. Computing assistance was obtained from the Health Sciences Computing Facility, UCLA, supported by the NIH Special Research Resources Grant RR-3.

39. Received for publication January 24, 1979.

40. Accepted for publication July 31, 1979. 